Convention 161 on 'Occupational Health Services' provides tools to qualify and quantify occupational health services which are 'entrusted with essentially preventive functions'.

Results The present coverage of services globally is presented and essential components of present practices are highlighted. Countries that have properly established services tend to have healthier workforce, lower number of problems, illnesses and injuries at work. The Public Health Care system and family doctors can significantly contribute to such occupational health services while they need access to knowledge, training and contacts with workplace problems. Basic Occupational Health Services can be established.

Conclusion The immediate reaction to problems caused by exposures to various risks at work is often first aid and treatment and usually just limited to that. There is a need to have a new focus and attention on the diagnosis, reporting and other proactive functions by health staff, including public health doctors, nurses or family doctors.

\section{1b MISSION IAOH-BOHS: OCCUPATIONAL HEALTH SERVICE DELIVERY FOR INFORMAL SECTOR WORKERS THROUGH PRIMARY CARE ECOSYSTEM}

R Parekh. Chair- Mission BOHS: Indian Association of Occupational Health (IAOH), Mumbai, India

\subsection{6/oemed-2018-ICOHabstracts.1188}

Over 400 million informal workers in India are deprived of organised occupational health care services. Challenges of dysfunctional occupational health care for such a large unorganised workforce stimulated the Indian Association of Occupational Health (IAOH) to launch Mission BOHS incorporating the concept of Universal Health Coverage and BOHS strategies of WHO, ILO, WONCA and ICOH. Considering the serious lacunae in availability of trained human resources in this field, training of primary care professionals in $\mathrm{OH}$ assumed particular significance both, in terms of its reach, and accessibility. A Task Force was appointed to study profile, size, characteristics of work and occupational health risks of leading 22 informal industries. The target audience for capacity building identified were Medical Officers of Primary Health Centres (PHC), Employees' State Insurance Hospitals and Family Physicians. Next step involved the creation and publication of 'Basic Occupational Health Services for Informal Industry: Manual for Primary Care Providers' in print and ebook versions. This manual was converted into audiovisual format for training videos screened via satellite for PHC staff during monthly district meetings. Free downloads of ebook were offered on IAOH website, as contact seminars were found to be less effective and more expensive. Pilot BOHS project has been launched in one state subsequently, followed by appointment of BOHS Missionaries across major states to advocate knowledge, attitudes and practices relevant to BOHS. The Primary Care ecosystem offers a potential model intervention in $\mathrm{OH}$ for the informal sector in developing countries. Mission BOHS, is work in progress and is expected to penetrate deeper with collaborations between IAOH and Central Labour Insitute, Director General of Factories, Labour Advisory Service, Indian Institute of Public Health.
1701C DEVELOPMENT OF OCCUPATIONAL ILLNESSES AND INJURIES RECOGNISING AND RECORD KEEPING TO STRENGTHEN OCCUPATIONAL HEALTH SERVICES DELIVERY AMONG PRIMARY CARE UNITS IN THAILAND

0 Untimanon*, K Sukanun, Pusanisa Chaladlard. Bureau of Occupational and Environmental Diseases, Department of Disease Control, Ministry of Public Health, Thailand

\subsection{6/oemed-2018-ICOHabstracts. 1189}

Introduction PCUs in Thailand are able to provide some occupational health services activities. Occupational diseases (OD) are difficult to diagnose for several reasons:

- the similarities in the clinical presentation and pathophysiology between occupational and non-occupational exposures;

- the long latency period between exposure and symptom onset;

- the multifactorial aetiology of many chronic diseases; and

- no data of work-related conditions. If PCUs could provide OD diagnosis, patients with suspected OD will be benefit from referral to an occupational medicine specialist for a more detailed assessment, under-report of OD and risk from work will be managed. This study aimed to develop OD recognising and record system to strengthen OHS data system.

Methods The screening questions were developed to identify potential occupational causes of symptoms. Meanwhile, Bureau of Occupational and Environmental Diseases has collaborated with the Health Data Centre (HDC) of the Ministry of Public Health to add the 14 common OD in the data system. PCUs were recommended to use such screening questions, provide OD diagnosis and record in the data system.

Results Screening questions include what kind of job patients have; whether their symptoms are worse at work; whether they are or have been exposed to dust, fumes, chemicals, or loud noise; whether their colleagues have similar symptoms and whether they think their health problems may be related to their works. Currently, 2031 (20.78\%) of total PCUs could use such questions to identify $\mathrm{OD}$ and add external cause ICD-10 code (Y96) to the record system. All data link to HDC therefore the national and local agencies could access OD statistics through HDC.

Conclusion Such screening questions are very useful and important for PCUs, especially when the diagnosis or aetiology is in doubt. Occupational health services among PCUs should be strengthened to obtain the quality data.

\section{1d UNIVERSAL HEALTH COVERAGE AND WORKERS' HEALTH DEVELOPMENTS IN INDONESIA}

Hanifa M Denny. Diponegoro University, Semarang, Indonesia

\subsection{6/oemed-2018-ICOHabstracts. 1190}

Introduction The social and health Insurance or universal health coverage for the Indonesian is BPJS. BPJS stands for Badan Penyelenggara Jaminan Sosial or The Social Security Organisation Body. The Indonesian army, police, civil employees, assistance recipients (PBI), and citizens in general are mandated to register with BPJS Kesehatan while the private company employees and expatriates who work in Indonesia 